Books, videos, CD-ROMs, DVDs and any

other relavent items submitted for a review

in the $B D J$ should be addressed to: Kate

Maynard, Assistant Editor, British Dental

Journal, NPG, 4-6 Crinan Street, London,

N1 9XW

\section{Standards in dentistry}

\author{
K. Eaton \\ UK: FGDP(UK) \\ price £26-FGDP (UK) members; \\ Ł39-non-members, pp 84 \\ ISBN 0954345142
}

Standards in dentistry is a unique package of standards and guidelines published by the Faculty of General Dental Practice (UK) for all members of the dental community. For a long time, there was a need for publication of such a document which could combine all previous guidelines and standards in dentistry.

On opening the manual the first thing that strikes you is the clear and impressive layout. The subject matter is comprehensive, well structured, and easy to read and understand. It is intended for both primary and secondary dental care practitioners and should lead to improved standards in dentistry.

The book is organised into five sections. The first two sections inform the reader about the aims of the publication and discuss the need for standards in dental practice, and there is also a brief explanation regarding the use of the manual and classification of quality standards.

The third section is comprised of an introduction to grading system in tables of treatment outcomes, and generic and non-generic clinical guidelines. Also four of the clinical topics are renamed in a very comprehensive and scientific manner.

The next section provides an overview of the GDC's guidance and the Department of Health requirements for clinical governance. It goes on to outline the FGDP (UK) key skills and to set out comprehensive lists of standards for dental practice.

The last section of the manual explains FGDP (UK) assessments and examinations. The career pathway provides support and development for general dental practitioners and primary care dentists. This section also gives an overview of all assessments of the FGDP (UK).

Kenneth Eaton, the Editor of Standards in dentistry, has put together an innovative manual of up-to-date knowledge. It assesses standards put forward by different bodies and organisations and explains their use, above all keeping within the limitations of the standards and outlines of the FGDP (UK).

This is a valuable addition to the texts available for the dental community. I therefore would not hesitate to recommend its inclusion on reading lists and in the libraries of all dental institutions.

\section{Planning and making crowns and bridges (fourth edition)}

\begin{tabular}{l}
\hline B. G. N. Smith, L. C. Howe \\
UK: Informa Healthcare \\
price £125.00, pp 326 \\
ISBN 0415398509
\end{tabular}

This is the latest edition of a well established textbook. The fourth edition is considerably enhanced by the inclusion of implants, which hitherto have not featured in this text. The book is well written and beautifully illustrated and the authors are to be commended for their pragmatic approach to the subject.

It is often said that success is a poor teacher and that we really only learn when things go wrong. The authors have taken this onboard because they have included illustrations of things that are not perfect and in this sense the book is clinically realistic and eminently practicable. This approach is commendable because when crown and bridgework are designed and prescribed for patients, a degree of compromise is often required particularly at the treatment planning stage and the authors have acknowledged this in the text.

The layout of the book is very user friendly and each section is preceded by some very helpful indications and contraindications for the various techniques described. These sections then go on to describe the different types of preparations and the clinical techniques required to realise successful results with each individual type of restoration. In addition there are helpful hints and tips for when things go wrong.

The structure of the text is logical, flowing and pitched at a perfect level for both undergraduate students and postgraduate students. Unusually the text is not referenced, which the authors have done deliberately as the book is not intended to be a reference text but rather a clinical guide or manual.

In summary this book is to be recommended for its very comprehensive approach to the subject, which is tempered with clinical realism.

P. A. Brunton

\section{Churchill's Pocketbooks: Clinical dentistry (third edition)}

\author{
I. G. Chestnutt, J. Gibson \\ UK: Elsevier \\ price $\mathrm{E} 22.99$, pp 591 \\ ISBN 0443102110
}

This is the third edition of a pocket book first published in 1998. In the preface of the first edition, the editors stated that the aims of the book were "to provide a readily accessible source of information when it is most needed, as a an aide memoire prior to carrying out clinical tasks or to enable students (at undergraduate and postgraduate level) to apprise themselves of important details prior to tutorials and seminars'. The third edition should continue to meet these aims and to maintain the ongoing success of the first two editions.

The book has 17 chapters written by 12 experts in their fields. As well as chapters on the recognised dental specialties, there are others covering: psychological aspects of care; history and examination; law ethics and quality dental care; drug prescribing and therapeutics; analgesia, sedation and dental anaesthesia; dental materials; general medicine of relevance to dentistry; and emergencies in dentistry. All are written in a concise, punchy style 

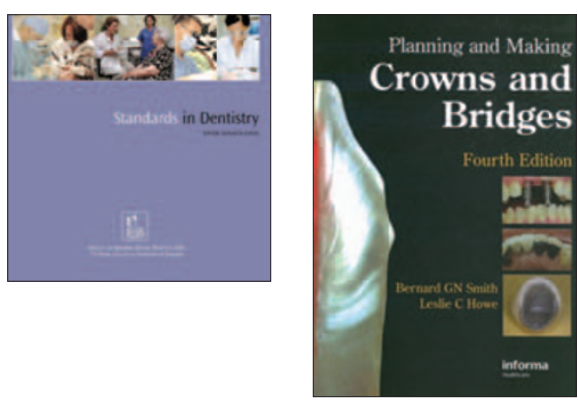

and provide the essentials of each topic area. Each chapter is clearly formatted, with logical use of subtitles and clear, simple diagrams. Clinical procedures, definitions and other key messages are identified in boxes separated from the main text. I found these particularly useful. For example, one box contained the toxic dose of various local anaesthetic preparations and the maximum volumes that can be used safely.

For those interested, suggestions for additional reading comprise one of the six useful appendices. Some readers might prefer to have the reading lists at the end of the relevant chapter to prevent the need for page flipping. Another of the appendices covers infection control which is covered more superficially than other important topics, although the author does refer the reader to BDA Advice Sheet A12 for more detail.

Overall, I can recommend this excellent book. The authors are to be congratulated for producing a concise text that dental and dental care professional students will find extremely useful, especially as revision notes. It will also be useful as a quick reference book for postgraduates, particularly those who have had some time away from clinical dentistry. My copy sits in my surgery and is already well-thumbed!

\section{T. A. Dyer}

\section{Panoramic radiology}

V. E. Rushton, J. Rout
UK: Quintessence
price £28.00, pp 145
ISBN 1850970807

This 148 page A5 format book, which forms part of the Quintessentials for General Dental Practitioners Series (volume 20 of 50), sets out to educate practitioners in the technique of Dental Panoramic Radiography (DPR), along with the interpretation of images and the justifications for taking them. The book is aimed at existing and future practitioners alike and claims that it is written in such
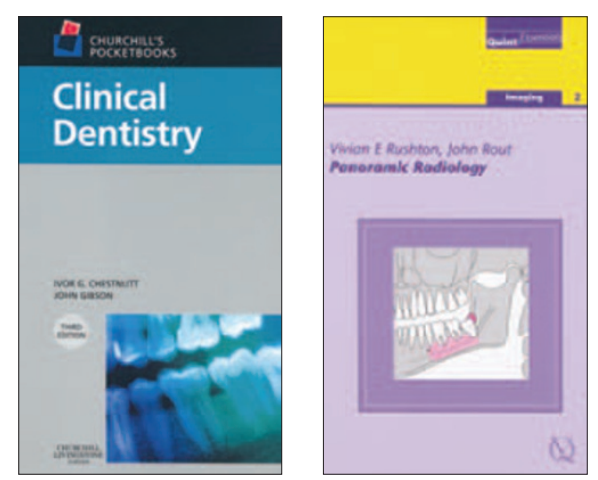

a way as to be useful to all members of the dental team. The book is priced at $£ 28$ which would seem a reasonable price for such a text.

The book begins with an explanation of the history of panoramic radiography which provides an engaging start and quickly develops to cover the techniques that should be used when taking DPRs. Most of the pages in these chapters contain diagrams which aid the understanding of the subject matter.

Chapters on radiation dose, use of DPR in general practice and quality assurance help to provide guidance as to when this technique is justified, as well as how to get the best images. The book also serves to suggest certain situations when alternative radiographic techniques are called for. Quality assurance is always of great importance and the chapter on this topic helps to shed light on a number of common problems that can affect the quality of panoramic radiographs.

The chapters on anatomy and radiographic interpretation of disease make for interesting reading and while the book does not claim to be an exhaustive text it does cover a number of the more common conditions that may be found on radiographic examination. The chapters contain a large number of example radiographs which are fully explained and illustrate the conditions clearly.

Any practitioner who wishes to undertake panoramic radiography in their practice has a clinical obligation to be aware of how to produce the highest quality diagnostic radiograph possible and to be able in turn to diagnose based on this. This book is a good reminder for qualified practitioners and a useful revision tool for undergraduates. On the whole this book is interesting and well written; it achieves what it sets out to do and provides a good overview of the subject. Those wanting an exhaustive text on the subject will find this book short of information; however for most practitioners it provides a readable, helpful overview and would prove a useful addition to the practice library.

E. Mein 